\title{
An Empirical Study on Fuzzy Comprehensive Evaluation of Red Tourism Resources Based on AHP
}

\author{
Rong Hu${ }^{1}$, Chaofeng Zhang ${ }^{2}$ \\ ${ }^{1}$ School of Mathematics, Sichuan University of Arts and Science, Dazhou, China \\ ${ }^{2}$ School of Finance-Economics, Yangtze Normal University, Chongqing, China \\ Email: ${ }^{\star}$ zbeyondiee@163.com
}

How to cite this paper: Hu, R. and Zhang, C.F. (2018) An Empirical Study on Fuzzy Comprehensive Evaluation of Red Tourism Resources Based on AHP. Applied Mathematics, 9, 171-177. https://doi.org/10.4236/am.2018.92012

Received: December 28, 2017

Accepted: February 25, 2018

Published: February 28, 2018

Copyright ( $) 2018$ by authors and Scientific Research Publishing Inc. This work is licensed under the Creative Commons Attribution International License (CC BY 4.0).

http://creativecommons.org/licenses/by/4.0/

\section{c) (i) Open Access}

\begin{abstract}
Red tourism, which is featured with spiritual culture, resource fusion and historical socialization, is a remarkable innovation with Chinese characteristics. It is the shinning point of China's tourism business development. This paper will show the objective and correct evaluation of red tourism resource. Firstly, it will create evaluation index system by theoretical analysis method and expert consultation method. Secondly, it will evaluate each object synthetically by fuzzy comprehensive evaluation method and analytic hierarchy process. Finally, through case study of General Zhang Aiping's, Former Residence in Dazhou, Sichuan Province, conclusion and related suggestion will be achieved.
\end{abstract}

\section{Keywords}

Red Tourism Resource, Fuzzy Comprehensive Evaluation Method, Evaluation Index, Analytic Hierarchy Process, Zhang Aiping's Former Residence

\section{Introduction}

Red tourism is one of the most significant features in China's old revolutionary base areas. Except carrying forward revolutionary spirit and culture, also it could bring considerable economical benefits for tourism region, which is one of the methods to improve old revolutionary base areas' culture and economy. In recent years, although red tourism had been developing boomingly, there still are several problems and shortages during the development, such as: the inadequacy in understanding importance of red tourism, the neglect in economical benefit brought by red tourism, the lagging in propagates of red tourism and so on. Until now, scholars had done lots of research work regarding the development of 
red tourism [1]-[8]. This paper will evaluate each object synthetically by fuzzy comprehensive evaluation method and analytic hierarchy process. And through case study of General Zhang Aiping's, Former Residence in Dazhou, Sichuan Province, conclusion and related suggestion will be achieved.

\section{Comprehensive Evaluation Index System for Red Tourism Resource}

The establishment of comprehensive evaluation index system for tourism resource should follow the rules of scientificalness, hierarchy, integrality, operability and comparability [1]. In this paper, we combine theoretical analysis method, expert consultation method and other related factors; comprehensive evaluation index system for red tourism resource is shown in Table 1.

\section{Research Method}

\subsection{Model of Fuzzy Comprehensive Evaluation}

The basic idea of the fuzzy comprehensive evaluation method is to follow the step of "qualitative-quantitative-qualitative", which is start with qualitative research, and quantitative processing, and then obtains qualitative evaluation result [1]. The concrete model factors including the followings [4]:

1) Establish rating object set $B=\left\{B_{1}, B_{2}, \cdots, B_{s}\right\}$, factor set $U=\left\{U_{1}, U_{2}, \cdots, U_{m}\right\}$, and comment set $V=\left\{V_{1}, V_{2}, \cdots, V_{n}\right\}$.

2) Evaluate fuzzy evaluation matrix $R=\left(r_{i j}\right)_{m \times n}$, here, $r_{i j}$ represents the membership degree of factor $U_{i}$ to comment $V_{j}$.

3) Establish the weight set $W=\left\{w_{1}, w_{2}, \cdots, w_{m}\right\}$ of each factor in $U$.

4) Build the fuzzy comprehensive evaluation model $C=W \cdot R$, and get the fuzzy evaluation result of all factors in $U$ set.

\subsection{Using Analytic Hierarchy Process (AHP) to Calculate Weight}

It is a very important step to determine the weight of evaluation index in fuzzy comprehensive evaluation model, and there are many methods to do it, such as

Table 1. Comprehensive evaluation index system for red tourism resource.

\begin{tabular}{|c|c|c|}
\hline First grade indexes & Second grade indexes & Third grade indexes \\
\hline \multirow{9}{*}{$\begin{array}{l}\text { Comprehensive } \\
\text { evaluation for red } \\
\text { tourism resource }\end{array}$} & \multirow{4}{*}{ Resource value } & Value of revolutionary historical culture \\
\hline & & Ornamental value \\
\hline & & Scientific value \\
\hline & & Educational value \\
\hline & \multirow{2}{*}{ Scale of scenic area } & Location combination of scenic \\
\hline & & Environmental volume of tourism \\
\hline & \multirow{3}{*}{ Ancillary enterprises } & Traffic \\
\hline & & Catering \\
\hline & & Tourist commodity \\
\hline
\end{tabular}


AHP, entropy method, factor analysis method etc. In this paper, we will use the AHP to determine the weight of each index. Specific steps are as follows:

1) Structure the pair-wise comparison matrix. The matrix $A=\left(a_{i j}\right)_{n \times n}$ is established using the relative importance of a criterion to other criteria established by Saaty $1-9$ scale. Here, $a_{i j}=w_{i} / w_{j}, w_{i}$ is the weight of criterion $i$, and $w_{j}$ is the weight of criterion $j$.

2) Compute the weight vector. Using MATLAB to calculate the maximum eigenvalue $\lambda$ of matrix $A$ and its corresponding characteristic vector (which is normalized), the vector is weight vector which represents the weight of each factor $C_{1}, C_{2}, \cdots, C_{n}$ on $O$.

3) Check the consistency of the pair-wise comparison matrixes through calculating the consistency index $C I$ and consistency ratio $C R$. The formula is

$$
C I=\frac{\lambda-n}{n-1}, \quad C R=\frac{C I}{R I}
$$

where $n$ is the order of matrix $A$, and $R I$ is the average random consistency index for matrices of order $n$, calculated as follows:

\begin{tabular}{ccccccccccc}
\hline$n$ & 1 & 2 & 3 & 4 & 5 & 6 & 7 & 8 & 9 & 10 \\
\hline$R I$ & 0 & 0 & 0.58 & 0.90 & 1.12 & 1.24 & 1.32 & 1.41 & 1.45 & 1.49 \\
\hline
\end{tabular}

When $C R$ is greater than $0.1, \lambda$ is not satisfied, and inconsistent judgments must be readjusted in order to improve the consistency.

4) Compute the combination weight vector. If the sequencing weight vector of the $(k-1)$ th layer factor towards the total goal is

$$
W^{(k-1)}=\left(W_{1}^{(k-1)}, W_{2}^{(k-1)}, \cdots, W_{n}^{(k-1)}\right)^{\mathrm{T}}
$$

The entire factors of the $k$ th layer towards the synthetic sequence vector $W^{(k)}$ of the total goal are given by the following equation:

$$
W^{(k)}=\left(P_{1}^{(k)}, P_{2}^{(k)}, \cdots, P_{n}^{(k)}\right) W^{(k-1)}=P^{(k)} W^{(k-1)}
$$

where $P^{(k)}$ is the sequencing weight vector of the $k$ th layer factor towards the $(k-1)$ the layer factor.

\section{Case Study}

This next will take the Zhang Aiping's former residence in Da Zhou as an example, using the fuzzy comprehensive evaluation model, which use the analytic hierarchy process to calculate weight, to evaluate the red tourism resources of Zhang Aiping's former residence. Specific steps are as follows.

\subsection{Data Source}

According to the red tourism resources evaluation index system, the main content of the research questionnaire is the satisfaction degree of the visitors to the evaluation index, and the grade option is set to be very satisfied, satisfied, gener- 
al, dissatisfied, very dissatisfied which is according to the Li Kete's five scale. A total of 200 questionnaires are distributed, 187 copies are collected, and 175 valid questionnaires are collected, get data as shown in Table 2.

\subsection{Determine the Index Weight}

According to the expert investigation method, the pair-wise comparison matrixes are established as follows:

$$
\begin{gathered}
A=\left[\begin{array}{ccc}
1 & 4 & 2 \\
1 / 4 & 1 & 1 / 2 \\
1 / 2 & 2 & 1
\end{array}\right] ; B_{1}=\left[\begin{array}{cccc}
1 & 2 & 5 & 3 \\
1 / 2 & 1 & 3 & 2 \\
1 / 5 & 1 / 3 & 1 & 1 / 2 \\
1 / 3 & 1 / 2 & 2 & 1
\end{array}\right] ; \\
B_{2}=\left[\begin{array}{cc}
1 & 1 / 2 \\
2 & 1
\end{array}\right] ; \quad B_{3}=\left[\begin{array}{ccc}
1 & 2 & 4 \\
1 / 2 & 1 & 2 \\
1 / 4 & 1 / 2 & 1
\end{array}\right] .
\end{gathered}
$$

The weight of each index as shown in Table 3.

\subsection{Fuzzy Comprehensive Evaluation}

The evaluation objects are $B_{1}, B_{2}, B_{3}$, evaluation Indexes are $U_{1}, U_{2}, \cdots, U_{9}$, and comment set $V$ contents very satisfied, satisfied, general, dissatisfied, and very dissatisfied. Let the membership degree $r_{i j}$ be the ratio of the number of factor $U_{i}$ to comment $V_{j}$ to the total number of people participating in the survey, then the fuzzy evaluation matrixes can be structured as follows:

$$
R_{1}=\left[\begin{array}{lllll}
0.26 & 0.40 & 0.20 & 0.10 & 0.04 \\
0.11 & 0.36 & 0.33 & 0.12 & 0.09 \\
0.15 & 0.37 & 0.31 & 0.11 & 0.06 \\
0.15 & 0.39 & 0.30 & 0.10 & 0.06
\end{array}\right],
$$

\begin{tabular}{|c|c|c|c|c|c|c|}
\hline & indexes & $\begin{array}{c}\text { Very } \\
\text { satisfied }\end{array}$ & Satisfied & General & Dissatisfied & $\begin{array}{c}\text { Very } \\
\text { dissatisfied }\end{array}$ \\
\hline \multirow{4}{*}{$\begin{array}{l}\text { Resource } \\
\text { value }\end{array}$} & $\begin{array}{l}\text { Value of revolutionary } \\
\text { historical culture }\end{array}$ & 45 & 70 & 35 & 18 & 7 \\
\hline & Ornamental value & 19 & 63 & 57 & 21 & 15 \\
\hline & Scientific value & 26 & 64 & 55 & 19 & 11 \\
\hline & Educational value & 27 & 68 & 53 & 17 & 10 \\
\hline \multirow{2}{*}{$\begin{array}{c}\text { Scale of } \\
\text { scenic area }\end{array}$} & $\begin{array}{l}\text { Location combination } \\
\text { of scenic }\end{array}$ & 18 & 59 & 61 & 21 & 16 \\
\hline & $\begin{array}{c}\text { Environmental } \\
\text { volume of tourism }\end{array}$ & 25 & 67 & 63 & 15 & 5 \\
\hline \multirow{3}{*}{$\begin{array}{l}\text { Ancillary } \\
\text { enterprises }\end{array}$} & Traffic & 16 & 46 & 73 & 19 & 21 \\
\hline & Catering & 22 & 59 & 62 & 23 & 9 \\
\hline & Tourist commodity & 9 & 43 & 63 & 36 & 24 \\
\hline
\end{tabular}

Table 2. The original survey data of comprehensive evaluation. 
Table 3. Evaluation index weight of red tourism resources.

\begin{tabular}{|c|c|c|c|c|c|c|c|c|}
\hline $\begin{array}{c}\text { Target } \\
\text { hierarchy A }\end{array}$ & $\begin{array}{c}\text { Rule } \\
\text { hierarchy B }\end{array}$ & & Neight & Indes & hierarcl & ny $U$ & Weight to B & $\begin{array}{l}\text { Weight } \\
\text { to A }\end{array}$ \\
\hline \multirow{9}{*}{$\begin{array}{l}\text { Comprehensive } \\
\text { evaluation for } \\
\text { red tourism } \\
\text { resource }\end{array}$} & \multirow{4}{*}{ Resource value } & \multirow{4}{*}{\multicolumn{2}{|c|}{0.5714}} & \multicolumn{3}{|c|}{$\begin{array}{l}\text { Value of revolutionary } \\
\text { historical culture }\end{array}$} & 0.4824 & 0.2757 \\
\hline & & & & \multicolumn{3}{|c|}{ Ornamental value } & 0.2718 & 0.1553 \\
\hline & & & & \multicolumn{3}{|c|}{ Scientific value } & 0.0883 & 0.0504 \\
\hline & & & & \multicolumn{3}{|c|}{ Educational value } & 0.1575 & 0.0900 \\
\hline & \multirow{2}{*}{$\begin{array}{c}\text { Scale of scenic } \\
\text { area }\end{array}$} & & \multirow{2}{*}{0.1429} & \multicolumn{3}{|c|}{$\begin{array}{c}\text { Location } \\
\text { combination of scenic }\end{array}$} & 0.3333 & 0.0476 \\
\hline & & & & \multicolumn{3}{|c|}{$\begin{array}{c}\text { Environmental } \\
\text { volume of tourism }\end{array}$} & 0.6667 & 0.0952 \\
\hline & \multirow{3}{*}{\multicolumn{2}{|c|}{$\begin{array}{l}\text { Ancillary } \\
\text { enterprises }\end{array}$}} & \multirow{3}{*}{0.2857} & \multicolumn{3}{|c|}{ Traffic } & 0.5714 & 0.1633 \\
\hline & & & & \multicolumn{3}{|c|}{ Catering } & 0.2857 & 0.0816 \\
\hline & & & & \multicolumn{3}{|c|}{ Tourist commodity } & 0.1429 & 0.0408 \\
\hline & \multirow{2}{*}{$R_{2}=$} & 0.10 & 0.34 & 0.35 & 0.12 & 0.09 & & \\
\hline & & 0.14 & 0.38 & 0.36 & 0.09 & 0.03 & , & \\
\hline & \multirow{3}{*}{$R_{3}=$} & 0.09 & 0.26 & 0.42 & 0.11 & 0.12 & & \\
\hline & & 0.13 & 0.34 & 0.35 & 0.13 & 0.05 & . & \\
\hline & & 0.05 & 0.25 & 0.36 & 0.21 & 0.14 & & \\
\hline
\end{tabular}

The weight of $U_{1}, U_{2}, U_{3}, U_{4}$ relative to $B_{1}$ :

$$
W_{1}=\left(w_{11}, w_{12}, w_{13}, w_{14}\right)=(0.4824,0.2718,0.0883,0.1575) ;
$$

The weight of $U_{5}, U_{6}$ relative to $B_{2}$ :

$$
W_{2}=\left(w_{21}, w_{22}\right)=(0.3333,0.6667) ;
$$

The weight of $U_{7}, U_{8}, U_{9}$ relative to $B_{3}$ :

$$
W_{3}=\left(w_{31}, w_{32}, w_{33}\right)=(0.5717,0.2857,0.1429) ;
$$

The weight of $U_{1}, \cdots, U_{9}$ relative to $A$ :

$$
W=(0.2757,0.1553,0.0504,0.0900,0.476,0.0952,0.1633 .0 .0816,0.0408) \text {. }
$$

The fuzzy evaluation result contains two parts: the target hierarchy and the rule hierarchy. The fuzzy sets of three rule hierarchy are calculated as follows:

$$
C_{i}=W_{i} R_{i}, \quad i=1,2,3
$$

And it can be calculated:

$$
\begin{gathered}
C_{1}=W_{1} R_{1}=(0.1910,0.3843,0.2605,0.1071,0.0571) ; \\
C_{2}=W_{2} R_{2}=(0.1295,0.3676,0.3562,0.09851,0.0495) ; \\
C_{3}=W_{3} R_{3}=(0.0955,0.2816,0.3910,0.1290,0.1029)
\end{gathered}
$$

Let $R^{*}=\left(\begin{array}{l}R_{1} \\ R_{2} \\ R_{3}\end{array}\right)$, the fuzzy sets of target hierarchy can be calculated as: 


$$
C=W R^{*}=(0.1549,0.3526,0.3114,0.1119,0.0691) .
$$

Finally, according to the Li Kete's five scales, the five comments are evaluated as Table 4:

Then the evaluation results are calculated:

$$
\begin{gathered}
E_{1}=5 \times 0.1910+4 \times 0.3843+3 \times 0.2605+2 \times 0.1071+0.0571=3.5449 \\
E_{2}=5 \times 0.1295+4 \times 0.3676+3 \times 0.3562+2 \times 0.0971+0.0495=3.4305 \\
E_{3}=5 \times 0.0955+4 \times 0.2816+3 \times 0.3910+2 \times 0.1290+0.1029=3.1380 \\
E=5 \times 0.1549+4 \times 0.3526+3 \times 0.3114+2 \times 0.1119+0.0691=3.4123
\end{gathered}
$$

It is shown in Table 5 .

\section{Result Analysis and Suggestion}

Based on the evaluation result, the comprehensive evaluation value $E$ for Zhang Aiping's, Former Residence, red tourism resource is 3.4123. According to evaluation standard, this red tourism resource is above average, which means that the development of it is reasonable and positive although some spaces for development and improvement exist.

The evaluation value for resource value, scale of scenic spot and auxiliary business are $E_{1}=3.5449, E_{2}=3.4305, E_{3}=3.1380$ respectively. Resource value $\left(E_{1}\right)$ is the best, which shows that it is the most obvious worth and contribution to comprehensive evaluation of this red scenic spot. According to the portion of four evaluation indexes, revolutionary historical culture value takes significant part. As the glorious history of General Zhang Aiping, it indicates that this red scenic spot contains rich revolutionary historical culture connotation, which has affected later generations positively too much. Evaluation value of scale of scenic spot is better than comprehensive evaluation value, which means that this spot

Table 4. Fuzzy score table of evaluation grades.

\begin{tabular}{cccccc}
\hline $\begin{array}{c}\text { Order of } \\
\text { evaluation }\end{array}$ & $\begin{array}{c}\text { Very } \\
\text { satisfied }\end{array}$ & Satisfied & General & Dissatisfied & $\begin{array}{c}\text { Very } \\
\text { dissatisfied }\end{array}$ \\
\hline Score & 5 & 4 & 3 & 2 & 1 \\
\hline
\end{tabular}

Table 5. Comprehensive evaluation results of red tourism resources.

\begin{tabular}{ccccccc}
\hline & \multicolumn{5}{c}{ fuzzy set Ci } \\
\cline { 2 - 6 } $\begin{array}{c}\text { Evaluation } \\
\text { object (Sorted) }\end{array}$ & $\begin{array}{c}\text { Very } \\
\text { satisfied }\end{array}$ & Satisfied & General & Dissatisfied & $\begin{array}{c}\text { Very } \\
\text { dissatisfied }\end{array}$ & $\begin{array}{c}\text { evaluation } \\
\text { results E }\end{array}$ \\
\hline $\begin{array}{c}\text { resource value (First) } \\
\text { scale of scenic area } \\
\quad \text { (Second) }\end{array}$ & 0.1910 & 0.3843 & 0.2605 & 0.1071 & 0.0571 & 3.5449 \\
$\begin{array}{c}\text { Ancillary enterprises } \\
\text { (Third) }\end{array}$ & 0.1295 & 0.3676 & 0.3562 & 0.0971 & 0.0495 & 3.4305 \\
$\begin{array}{c}\text { Comprehensive } \\
\text { evaluation value }\end{array}$ & 0.1549 & 0.3526 & 0.3114 & 0.1119 & 0.0691 & 3.4123 \\
\hline
\end{tabular}


possesses preferable capacity for visitors. Actually, it covers an area of around $500 \mathrm{Mu}$ to be able to bear more than 10 thousand tourists' visiting at the same time. Tourism auxiliary business is the worse, which is lower than comprehensive evaluation value to bring negative effect for comprehensive evaluation. So auxiliary business needs to be developed and improved dedicatedly by related parties. Among traffic, catering and tourism goods, catering takes the highest portion and traffic takes the lowest portion. It indicates that traffic of this spot is relatively good, but catering and tourism good is poor, which should be improved as soon as possible.

\section{Fund}

This research was supported by scientific research fund of Sichuan Provincial Education Department of China (18ZA0416; 16ZA0357).

\section{References}

[1] Jia, H.-M. (2009) The Tourism Resources Appraisal Based on Fuzzy Synthetically Evaluation Model. Science Technology and Industry, 9, 27-31.

[2] Tang, L. and Li, M.-F. (2007) Study on Comprehensive Evaluation of Red Tourism Resources Based on AHP-Taking Xingan County as a Case. Journal of Lanzhou Commercial College, 23, 47-51.

[3] Jiang, B. and Zheng, H.-H. (2013) The Study on Service Quality Evaluation Models Based on the "8 Factors" of Destination. Commercial Research, 8, 149-152.

[4] Yang, C.-L. (2010) Study on Comprehensive Evaluation Model of Tourism Resources. Journal of Kunming University, No. 1, 16-21.

[5] Lian, Y. and Wang, X. (2014) A Case Study and Application of Customer Satisfaction Evaluation System in Tourist Destinations Based and TDCSI. Tourism Tribune, 19, 9-13.

[6] You, D.-M. and Xu, F. (2003) The Evaluation on Economic Benefit of Regional Tourism Based on Information Entropy. J.Cent.South Univ, 9, 641-643.

[7] Liu, Y., Liu, X.-J. and Liang, Z.-Z. (2012) Evaluation of Henan Sports Tourism Resources Based on AHP and Fuzzy Mathematics. Areal Research and Development, 31, 108-112.

[8] Lu, S. and Wang, B.-P. (2014) Evaluation of Tourism Climatic Comfortable Index in Xian Based on Fuzzy Mathematics. Chinese Agricultural Science Bultin, 30, 276-283. 